\title{
El Decreto sobre Ordenación provisional de las Haciendas locales y el impuesto sobre solares sin edificar
}

El̂ arbitiro municipal sobre los solares sin edificar fué creado por la Ley de I2 de junio de I9I I que suprimió el impuesto de consumos, sal y alcoholes. El artículo $8 .^{\circ}$ le señalaba como límite máximo el 5 por 1.000 del valor en venta, y disponía que el establecimiento del arbitrio llevaba aparejada la supresión de los recargos municipales sobre la cuota del Tesoro, la cual sería fijada con arreglo a la extensión superficial del terreno y como si fuera tierra de labor de la mejor clase del término municipal.

Se trata de un tributo que grava el valor, a diferencia de la contribución territorial que grava el producto real o supuesto.

La nueva regulación del arbitrio ha venido a modificar, en la mayor parte de los casos con ventaja, la contenida en el Reglamento de 29 de junio de I9I I, dictado para la aplicación de la Ley.

La parte procesal se ha simplificado, facilitándose notablemente la tramitación. No es necesario formar el avance del plano parcelario y, después, el definitivo por manzanas, ni distinguir la evaluación por parcelas y la de zonas o complexos con intervención de la Junta, ni es necesario determinar si la conservación del registro ha de hacerse de manera permanente o por revisiones periódicas.

El artículo 22 del Reglamento exigía que el acuerdo del Ayuntamiento estableciendo el arbitrio contuviera determinadas circunstancias, todas las cuales se incluían por punto general en la Ordenanzå, aun cuando no estuviera así exigido de una manera taxativa. En la actualidad ha desaparecido esa exigencia y la Ordenanza ha- 
brá de ajustarse a los particulares del artículo 267 del Decreto, sin perjuicio de los demás que la Corporación estime pertinentes.

Se modican las normas para formar el registro de solares, y ya no se exige que conste de dos documentos, relación de inmuebles con expresión de los nombres de los propietarios y de los valores, y padrón de las personas obligadas al pago de las cuotas, sino que, a tenor del artículo 88, podrá constar de uno sólo, en el que figuren: los solares objeto del arbitrio, la extensión superficial (parece natural que esta circunstancia conste a continuación de cada solar, aun cuando el artículo la enumera la última), los valores base del mismo y las personas obligadas al pago. Queda suprimida la Junta, que constituía una complicación innecesaria.

Las tres operaciones de inclusión de los inmuebles sujetos al arbitrio, estimación de superficies y estimación de valores pueden simultanearse, según el artículo 88 del Decreto. Ahora bien, esta simultaneidad no resulta completamente clara, puesto que los artícudos 88 y 89 disponen que el avance del registro y la estimación de superficies se expondrán al público por espacio de quince días, durante los cuales podrán los interesados legítimos formular reclamaciones, que habrán de versar, en cuanto al primero, sobre la inclusión o exclusión de los terrenos. $\mathrm{Y}$ aun el artículo 90 complica más la dificultad al declarar que, terminada la estimación de superficies, se procederá a la de valores, la cual a su vez será objeto de exposición al público durante el mismo plazo y con idénticos fines. Del conjunto de estos preceptos parece resultar la necesidad de que las tres operaciones se hagan, no simultánea, sino sucesivamente. Si lo que se quiere decir con la frase "que administrativamente podrán simultanearse" es que la Administración municipal puede, si asi le conviene, realizar las tres operaciones a la vez, sin perjuicio de hacerlas públicas sucesivamente a los efectos de las reclamaciones, sobraba la autorización, porque se trata de una operación de orden interno sin ninguna trascendencia.

Para interpretarlos de modo que quepa ponerlos de acuerdo con el artículo 88, habrá que pensar en la necesidad de realizar a la vez las tres operaciones, las que se harán conocer al público a partir del mismo momento, para llevar a la práctica las alteraciones en los tres 
documentos, con la natural repercusión de los unos en los otros. Si se excluye un solar en el avance es natural que se suprima de los otros dos; si se admite la modificación de una superficie, habrá de traducirse en la estimación.

En cuanto a los recursos se varía el sistema, porque, mientras las reclamaciones presentadas contra el avance las resolvía la Administración de Rentas Públicas, pudiendo recurrirse contra sus resoluciones al Delegado de Hacienda, y las presentadas contra la evaluación eran objeto de acuerdo del Ayuntamiento, recurrible ante el mismo Delegado, en la actualidad todas las resoluciones son de carácter municipal y se recurren ante el Tribunal provincial económico-administrativo.

Una de las modificaciones más importantes es la variación de lo que se entiende por solar.

El Reglamento provisional de administración, investigación y. cobranza de la contribución sobre edificios y solares, de 24 de enero de I894, había dicho que eran solar los terrenos que no producen renta alguna y que están enclavados en el interior de las poblaciones, en su zona de ensanche o dentro de la línea de perímetro de las edificaciones realizadas o comprendidas en la zona del extrarradio.

El artículo 23 del Reglamento de 29 de junio de I9I I los vino a definir, a los efectos del arbitrio, diciendo que son los terrenos que tengan ese carácter con arreglo a las disposiciones que regulen la contribución territorial, riqueza urbana.

"En consecuencia, se comprenderán como tales los terrenos edificables enclavados en el término municipal, que tengan uno o más de sus lados formando línea de fachada en una o varias vías públicas urbanizadas en todo o en parte, o sea aquellas en que estén instalados o se presten todos los servicios municipales, o, cuando menos, los de alumbrado, afirmado del pavimento y encintado de aceras.

En las grandes extensiones de terrenos que por su situación y condiciones quedan comprendidos en la definición de solar, no se considerará como tal, a los efectos contributivos, más que la faja de terreno lindante con la vía pública en un ancho que no podrá exceder de la longitud de la línea de fachada.

No obstará para su consideración como solares el que existan 
construídos en los terrenos, cobertizos, tinglados, secaderos, pabellones $\mathbf{u}$ otras obras análogas de carácter provisional ni que se dediquen a depósitos de madera, encierro o pastos de ganados o cualquiera otro aprovechamiento agrícola o pecuario, siempre que estén enclavados en zona urbanizada en las condiciones referidas anteriormente."

Esta definición se hallaba inspirada en el artículo 25 del Real decreto de 14 de agosto de I900, "Instrucción provisional para la formación del registro fiscal de edificios y solares".

El artículo 407 del Estatuto municipal varió el concepto de solar, adaptando el mismo contenido en el 386 , a los efectos de transformar la cesión del 20 por roo de la cuota del Tesoro de la contribución territorial riqueza urbana, en un arbitrio sobre el valor de los terrenos estén o no edificados. Conforme a este precepto son solares todos los terrenos situados en el casco de la población y, fuera de él, los demás terrenos cuyo valor corriente en venta exceda del duplo del que resulte de capitalizar la renta que fuera susceptible de producir supuesto su aprovechamiento agrícola y en las condiciones previstas para la valoración de la riqueza rústica.

El Ministerio de Hacienda dictó, en 12 de junio de I925, una Real orden en la que con carácter general resolvía: I. ${ }^{\circ}$ Que deben ser considerados como solares no edificados los enclavados en el casco de la población no ocupados por construcción o instalación que excluyan el aprovechamiento agricola de aquéllos o por edificaciones de carácter temporal, cuando el producto de éstas, a los efectos de la contribución territorial, exceda del 5 por roo del valor en venta del solar; y $2 .^{\circ}$ Los situados fuera del casco, que tengan la condición de tales, según el apartado B) del número $3 .^{\circ}$ del artículo 386 del Estatuto municipal y no estén ocupados como se indica en el número $\mathbf{r}^{\circ}$.

Este concepto fué recogido en el artículo $4^{\circ}$ del Reglamento de 3 de abril de 1925 y en el $7 .^{\circ}$ del de 30 de mayo de 1928 sobre formación del catastro parcelario, que definen el solar como el terreno propio para ser edificado, que por hallarse enclavado dentro del casco de la población o por ser inmediato a calles urbanas o zonas urbanizadas haya adquirido un valor notoriamente superior al que correspondería como terreno de labor. 
La Instrucción de ro de septiembre de 1917, modificada por la R. O. de 29 de agosto de 1920 y puesta en vigor nuevamente por la Ley de 6 de agosto de 1932, dice que son solares:

I. Los terrenos edificables que no producen renta alguna y que están enclavados dentro de la línea perimetral del casco de las poblaciones, según el plano levantado por el Instituto Geográfico, que ha de servir de base a los trabajos de avance catastral, siempre que tengan uno o más de sus lados formando línea de fachada a una o más vías públicas o particulares o trozos de las mismas que estén urbanizados, considerándose como tales aquellos que tengan todos los servicios municipales, o, por lo menos, los de alumbrado o encintado de aceras o afirmado.

2. Los terrenos enclavados en la zona de Ensanche de las poblaciones y que estén en las circunstancias del párrafo anterior. En las manzanas cuyas calles circundantes no estén todas abiertas o urbanizadas, sólo tributará como solar una faja de terreno cuya línea será la de la fachada a la vía o trozo de vía que esté urbanizada con un fondo igual al del fondo de la manzana en proyecto.

$3^{\circ}$ Los terrenos que en la misma situación que los anteriores estén dedicados a parques, jardines, huertos, talleres de cantería, encierro y pastos de ganado o cualquier otro aprovechamiento análogo.

La Ley de ordenación de solares de 15 de mayo de 1945, reproduciendo en cierto modo la Instrucción de 1894, considera como tales los terrenos no edificados sitos en el interior de las poblaciones o en las zonas de ensanche o extensión de las mismas, que estén afectados por planes de ordenación aprobados.

De estos antecedentes resultan dos criterios para la determinación de lo que se considera solar: uno, fundado en la situación del terreno y sus características (artículo 23 del Reglamento de 29 de junio de I9I I y 25 del R. D. de I4 de agosto de I90o), que quedan reducidas en la Ley de ordenación de solares a hallarse enclavados en el interior de las poblaciones o en zonas de ensanche o extensión, afectadas por planes de ordenación aprobados legalmente, y otro, fundado en el valor (artículo 386 del Estatuto municipal), 
con la variante contenida en el artículo $44^{\circ}$ del Reglamento de 3 de abril de 1925 y $77^{\circ}$ del de 30 de mayo de 1928 de que aquél esté producido por hallarse situado el terreno en determinadas zonas.

Entre ambos criterios, el Decreto que comentamos vuelve sobre el del Reglamento de I9I I, reproduciendo el artículo 21 de la Instrucción citada de 29 de agosto de 1920, puesta en vigor por Ley de 6 de agosto de 1932.

Es evidente que, con la variación del concepto, la Administración municipal verá disminuído el producto del arbitrio, porque dejarán de considerarse como solares terrenos que antes tenian esta consideración.

El criterio del Estatuto tiene en su abono que, tratándose de una carga sobre el valor del terreno, es natural que grave a todos aquellos que alcancen un límite superior al que supone el aprovechamiento agricola. El otro criterio, que sintéticamente pudiéramos decir que se funda en las urbanizaciones realizadas o en proyecto, cometerá a veces injusticias, ponque aquéllas producen unos efectos directos e inmediatos, y otras, mediatos e indirectos, y cabe pensar en la posibilidad de que terrenos situados fuera de la zona de que se trata, obtengan aumentos de valor superiores a otros que se encuentren dentro de ella con todas las características de solar fijadas por la ley. Sin embargo, nosotros lo estimamos más justo. El adoptado por el Estatuto podría serlo a los efectos de transformar la participación del 20 por ciento de la contribución territorial, riqueza urbana, en un arbitrio sobre el valor de los terrenos edificados o sin edificar, pero no to es como base del que ahora nos ocupa; el solar se caracteriza fundamentalmente por la posibilidad de ser destinado a la edificación, y no es justo incluir en esta clasificación a terrenos que no reúnen las indispensables condiciones y a los cuales el propio Ayuntamiento, perceptor de la exacción, negaría el permiso necesario para ser edificados por carecer de los más elementales servicios por no ajustarse a alineaciones aprobadas. El artículo 87 viene a confirmar este razonamiento, al declarar exentos los terrenos que, aun teniendo la consideración de solares según el arículo 82, no sean sus- 
ceptibles de edificación por existir planes, ordenaciones o resoluciones administrativas que la prohiban.

El artículo 23 del Reglamento distinguía los terrenos dedica. dos a jardines, según que estuviesen o no anejos a las viviendas, como ya lo había hecho la regla octava del artículo $9 .^{\circ}$ del $\mathrm{R}$. D. de 5 de enero de I9II, que contenía las bases para realizar un nuevo repartimiento de la contribución territorial de acuerdo con la Ley de 29 de diciembre de I9Io, y declaraba exentos a los primeros del arbitrio de solares. En cambio, el R. D. de 3 de abril de 1925 y el Reglamento de 30 de mayo de 1928, fieles al criterio de fundar la calificación de solar en el valor de los terrenos, consideraba como tales a los jardines, siempre que por razón de las obras de jardinería hubieren adquirido un valor notoriamente superior al que les correspondería como terrenos de labor.

El Decreto de Haciendas locales no hace distinción alguna sobre este punto, pero entendemos que en virtud de lo dispuesto en la octava de sus disposiciones transitorias habrá que estar, ante esta omisión, a lo que dispone el Reglamento. En cambio, autoriza en el párrafo tercero del artículo 87 que se pueden declarar exentos en la Ordenanza los jardines que sean estimados de interés $\mathbf{u}$ ornato público.

Hay una diferencia entre el Reglamento de I9II, la Instrucción provisional de 1900 -en que ya dijimos se hallaba inspirado- y el Decreto último, que aun cuando a primera vista parece leve, puede tener a veces consecuencias importantes en la práctica.

La Instrucción exige, para considerar una calle urbanizada, que tenga por lo menos los servicios municipales de alumbrado o afirmado y encintado de aceras; es decir, que son dos conceptos separados por una conjunción disyuntiva: "alumbrado o afirmado y encintado de aceras". Cualquiera de los dos servicios que exige es suficiente. El Reglamento de IgI I suprime la conjunción y exige "alumbrado, afirmado del pavimento y encintado de aceras", o sean los tres. El Decreto borra la conjunción copulativa y emplea đos disyuntivas: "Alumbrado o encintado de aceras o afirmado". Con la existencia de cualquiera de los tres servicios basta para que la calle se considere urbanizada. 
El tipo máximo de gravamen se conserva en el 5 por 1.000 sobre el valor corriente en venta del solar, pero cabe establecer con carácter ordinario un recargo del 100 por ıoo, que equivale al que autorizó el artículo 235 del Estatuto provincial a las Diputaciones, y que ahora ha quedado suprimido. $Y$ otro especial del 75 por 100 de la cuota máxima del arbitrio para destinarlo exclusivamente a la construcción de viviendas económicas, que es repetición del ya autorizado por la Ley de 27 de agosto de $\mathbf{9} 932$.

Entre los recursos especiales para la amortización de empréstitos figura en el artículo 169 del Decreto un arbitrio sobre los solares edificados o sin edificar análogø al que autorizaba el artículo 386 del Estatuto a los Ayuntamientos concesionarios del 20 por Ioo de la cuota del Tesoro riqueza urbana que quisieron transformar este gravamen. De alí se transcribe el concepto de lo que se considere como solar edificado, la base del arbitrio y la exención absoluta o perpetua de los terrenos que se hallen exentos de contribución territorial. El tipo de imposición, que entonces no podía exceder del I por I00, tiene ahora como límite el 0,25 , debiendo ser, también como entonces se hallaba dispuesto, idéntico para todos los solares del término municipal.

Uno de los recursos que señala el artículo 165 del Decreto para atender a las obligaciones del presupuesto especial de Ensanche, trasladado del artículo I 3 de la Ley especial de 26 de julio de I892, es un recargo del 4 por Ioo sobre los líquidos imponibles, que a efectos de la contribución territorial riqueza urbana corresponda a las fincas comprendidas en el Ensanche. Este recurso, según el artículo 86, es incompatible con el arbitrio de solares, precepto que aparta de tributar por este concepto en las grandes poblaciones una importante cantidad de terrenos sin que se nos alcance el fundamento.

El artículo 359 del Estatuto les eximía de ser gravados con las contribuciones especiales que se refieran a obras, instalaciones o servicios ejecutados por el Ayuntamiento y consistentes en apertura de calles y plazas, ensanche, alineaciones y prolongaciones de las existentes, rectificación de rasantes en cuanto mejoren sensiblemente las condiciones del tráfico, construcción y reparación de alcan- 
tarillas, primer establecimiento de aceras y del pavimento, y primer establecimiento de alumbrado público, mientras subsista el recargo del 4 por 100.

El artículo 166 del Decreto permite elevar este recargo hasta el límite máximo del 5,50 por 100 en cada uno de los solares en la zona de Ensanche, enclavados en manzanas totalmente urbanizadas, pero da mayor amplitud a la excepción de las contribuciones especiales para obras $o$ instalaciones municipales, declarando que serán siempre incompatibles con el recargo, con lo que los citados terrenos resultan doblemente favorecidos.

El recargo del 4 por Ioo es uno de los recursos del Ensanche. El artículo $6 .^{\circ}$ de la citada Ley de 26 de julio de 1892 señala como de cargo de los fondos de ese presupuesto especial el importe de las obras de urbanización, las cuales comprenderá la apertura de calles, plazas o trayectos que comuniquen o unan la población antigua con la moderna de aquél, la red de alcantarillado, la instalación de agua, el afirmado y empedrado, las aceras y el alumbrado, y el artículo 15 obliga a los Ayuntamientos a cuidar, bajo su responsabilidad, de que los recursos que se concedan no queden afectos a obligación alguna que no tenga por objeto el inmediato, directo y exclusivo beneficio de las zonas respectivas.

Serán de cuenta del presupuesto general municipal, según dispone el artículo 17 , el entretenimiento y conservación de los servicios y obras de cada calle, plaza o paseo del Ensanche desde que con los fondos especiales de éste se haya hecho la instalación de los servicios u obras, y el artículo 38 del Reglamento de $3 \mathrm{I}$ de mayo de 1893 viene a desarrollar esta doctrina disponiendo que son cargo del Ensanche todas las obras que se hagan dentro de su perímetro y que, terminada la instalación de un servicio en una vía del Ensanche, el entretenimiento del mismo será de cuenta del presupuesto general del Municipio, y el artículo i9 encomienda a la Comisión velar muy especialmente para que las cantidades consignadas para el Ensanche no sean aplicadas a fines distintos.

Se distingue claramente entre las obras del Ensanche, atendidas con sus fondos, y las que debe sufragar el presupuesto del Interior, aun dentro de una misma zona. Las primeras son, en términos ge- 
nerales, todas las realizadas para establecer los servicios; las segundas, las que tienden a la conservación, reparación y reposición de los servicios. Esta diferenciación justifica la incompatibilidad del recurso del 4 por 100 con las contribuciones especiales establecidas por el artículo 339 del Estatuto, pero no justifica la del recargo con el impuesto de solares y con las contribuciones especiales por obras, que por no ser de primer establecimiento, habrán de ser sufragadas con los recursos de los presupuestos municipales ordinarios o extraordinarios. Según nuestra modesta opinión, que admite todas las que puedan exponerse en contrario, ya que no estamos definiendo dogmas, sino razonando criterios, cuya falibilidad admitimos de antemano.

\section{Mariano Berdejo Casañal.}

Secretario del Ayuntamiento de Madrid. 